Kortrijk. Clin. Chim. Acta, 78: 121 (1977).

19. Van Biervliet, J. P. G. M., and Staal, G. E. J.: Excessive glycogen storage in glucose phosphate isomerase deficiency. Acta Paediat. Scand., 66: 311 (1977).

20. Van Biervliet, J. P. G. M., Vlug, A., Bartstra, H., Rotteveel, J. J., De Vaan, G. A. M., and Staal, G. E. J.: A new variant of glucose phosphate isomerase deficiency. Humangenetik. 30: 35 (1975).

21. Van Biervliet, J. P. G. M., Van Milligen-Boersma, L., and Staal, G. E. J.: A new variant of glucose phosphate isomerase deficiency (GPI Utrecht). Clin. Chim. Acta, 65: 157 (1975).

22. Vives-Corrons, J. L., Rozman, C., Kahn, A., Carrera, A., and Triginer, J.
Glucose phosphate isomerase deficiency with hereditary hemolytic anemia in a Spanish family: Clinical and familial studies. Human Gener., 29: 291 (1975).

23. This work was supported by Grant CRL 76-5-110 from INSERM. We are very grateful to Mrs. M. Urbanek for the typing of the manuscript.

24. Requests for reprints should be addressed to: A. Kahn, M.D., Ph.D., Institut de Pathologie Moléculaire, 24, rue du Faubourg Saint-Jacques 75014 Paris (France).

25. Received for publication February 8,1977

26. Accepted for publication March 15, 1977.

\title{
Quantitation of Renal Antigen Excretion in the Urine of Normal Children and of Children with Various Renal Diseases. I. Quantitation of Renal Antigens in Random Urine Samples
}

\author{
E. GAZIT, Y. ROTEM, AND H. BOICHIS'(27)
}

Department of Pediatrics "C," Department of Pediatrics "B," and the Pediatric Renal Unit, Chaim Sheba Medical Center, Tel Hashomer and Sacker School of Medicine, Tel-Aviv University, Tel-Aviv, Israel

\section{Summary}

This study reports a serologic method for the measurement of kidney-derived antigens in the urine of healthy children and of children with renal diseases. Two hundred twenty patients were studied. Four groups were recognized: group $A$, patients with no evidence of renal disease; group $B$, patients with past history of active urinary tract infection; group $C$, patients with active urinary tract infection; group $D$, patients with other renal diseases.

Urinary renal antigen concentration was tested by the complement fixation method, in which titers of antigens in the urine were compared with a standard human renal antigen extract. The distribution of renal antigen concentrations in group $C$ differed significantly $\left(P\left(\chi^{2}\right)\right.$ less than 0.001$)$ from the other three groups. About $85 \%$ of patients in groups $A, B$, and $D$ had levels below $0.6 \mathrm{mg} / \mathrm{ml}$, whereas in group $C$ only $53 \%$ of patients had similar concentrations. After factoring the results by the urinary concentration of creatinine, $85 \%$ of patients in group $C$ had antigen levels above $0.6 \mathrm{mg} / \mathrm{ml}$ as opposed to $24 \%, 44 \%$, and $27 \%$ in groups $A, B$, and $D$, respectively. The results of the study are consistent with the assumption that the rate of discharge of renal antigenic material in the urine is accelerated in certain renal diseases.

\section{Speculation}

Titers of renal antigen in urines of patients with urinary tract infection may differentiate parenchymal disease from lower tract disease. Monitoring of the pattern of renal antigen excretion may provide an index for optimal duration of antibacterial therapy in pyelonephritis.

Investigators have long been trying to find satisfactory methods for the assessment of the activity of renal diseases and the extent of ongoing organ injury. Indirect criteria such as blood chemistries, various renal functions, intravenous pyelography, and even renal biopsy are not always subtle enough to determine progression of disease.

Attention has recently been focused on the urinary excretion of protein under both normal and pathologic conditions (3). Most of these proteins are derived from the plasma $(2,8)$, although some have been identified as tissue components, of which minute amounts are excreted normally in the urine $(5,9$, 13). In the course of some pathologic conditions and during experimental renal disease, the amount of tissue components in the urine was found to increase markedly $(1,6,17)$. Some of these were identified as having renal antigen specificity. Boss and his collaborators $(5,6,17)$, as well as Antoine et al. (1), concluded that repeated determination of the renal antigens excreted in the urine of a patient might prove of value both as a diagnostic aid and for assessment of prognosis.

This reports a serologic method for the measurement of kidney-derived antigens in the urine of healthy children and of children with renal diseases.

\section{MATERIALS AND METHODS}

\section{PATIENTS}

Two hundred twenty consecutive patients attending the pediatric renal outpatient clinic were studied. They were of both sexes and their ages ranged from 6 months to 12 years. The urine samples were given running code numbers, and their records were referred to only after the completion of the laboratory investigation. Four groups of patients were recognized: group $A$, 80 patients with no evidence of renal disease; group $B, 60$ patients with a past history of urinary tract infection, with or without malformation of the urinary tract, but no evidence of 
active infection at the time of the testing; group $C, 26$ patients with active urinary tract infection as manifested by the presence of more than 20 leukocytes/high power field in the spun urinary sediment, with more than 100,000 colonies/ml of the same organism on repeated urine cultures. Some of the patients in this group had urinary malformations and/or vesicoureteral reflux; group $D, 54$ patients with various renal diseases other than urinary tract infection - glomerulonephritis, various forms of the nephrotic syndrome, tubulopathies, as well as malformations of the urinary tract with no evidence of infection.

\section{PREPARATION OF ANTIGEN AND ANTISERUM}

A normal, surgically removed human kidney (this was one of two cadaver kidneys removed en bloc for the purpose of transplantation, for only one of which a suitable recipient was found) was homogenized in a commercial Waring Blendor, using icecold $0.85 \% \mathrm{NaCl}$ in a $10: 1(\mathrm{v} / \mathrm{w})$ ratio. The mixture was centrifuged in an International refrigerated centrifuge (model B-20, International Equipment Co., Needham Heights, Mass.), at $10,000 \mathrm{rpm}$ for $30 \mathrm{~min}$. The supernatant was collected and lyophilized. The resultant powder is hitherto referred to as "renal antigen."

Randomly bred albino rabbits, weighing approximately $2 \mathrm{~kg}$, were immunized by the following method: (l) three weekly subcutaneous injections of $10 \mathrm{mg}$ renal antigen emulsified with complete Freund's adjuvant (Difco Laboratories, Detroit, Mich.), (2) followed by two weekly intraperitoneal injections of $10 \mathrm{mg}$ of the renal antigen dissolved in $2 \mathrm{ml}$ of $85 \% \mathrm{NaCl}$, (3) 10 days later, blood was withdrawn from the heart, and serum was pooled and kept at $-20^{\circ} \mathrm{C}$, until used.

\section{ABSORPTION OF ANTISERUM}

In an attempt to remove all other "anti-human" components, aliquots of $100 \mathrm{ml}$ pooled rabbit serum were incubated with a mixture of $1 \mathrm{~g}$ each of lyophilized human plasma, liver, and spleen. In the course of the study it was found that identical absorption results could be achieved by incubating the pooled rabbit serum with $3 \mathrm{~g}$ lyophilized human plasma only. The absorption was performed in the following manner. Incubation at $37^{\circ}$ for $1 \mathrm{hr}$, followed by an overnight incubation at $4^{\circ}$; the mixture was centrifuged at $15,000 \mathrm{rpm}$, the supernatant was collected, inactivated at $56^{\circ}$ for $30 \mathrm{~min}$, divided into small aliquots, and stored at $-20^{\circ}$. The resultant antiserum did not cross react with any other human tissue on repeated examinations.

Urine samples were collected in sterile containers after proper cleaning of genitalia by trained nurses. Part of the sample was used for bacteriologic culture and routine microscopic examination, as well as for protein and creatinine determination. Aliquots of $10 \mathrm{ml}$ were centrifuged to remove nonsoluble particles, transferred into dialysis bags (Union Carbide Corporation Food Product Division, Chicago, Ill.), and dialyzed overnight against distilled water in the cold. On the following day the bags were pervaporated against a fan to reduce volume, and dialyzed for an additional $24 \mathrm{hr}$. On the third day, the content was shell-frozen in $20 \mathrm{ml}$ glass tubes and lyophilized. The remaining powder was redissolved in $0.5 \mathrm{ml} 0.85 \% \mathrm{NaCl}$, transferred into small glass tubes, and kept at $-20^{\circ}$ until used. Repeated freezing and thawing, avoided as much as possible, did not reduce the antigen titer.

\section{COMPLEMENT FIXATION}

Reagents. (1) Sheep blood was collected in Alsevers' solution and kept in the refrigerator at $4^{\circ}$ for at least 1 week before use. (2) Rabbit hemolytic serum (Wellcome Reagents Ltd., Wellcome Research Laboratories, Backenham, England), was used as hemolytic antibody and titered according to Kabat (11). The optimal dilution was $1: 1000$. (3) Normal human serum was used as source of complement. Blood was obtained from normal volunteers, left at room temperature for $60 \mathrm{~min}$ for clot formation, and centrifuged in the cold; aliquots of the serum were stored at $-80^{\circ}$. Titration of complement was carried out at $\mathrm{pH}$ 7.4 in Veronal buffer containing magnesium and calcium salts (11). (4) Antiserum titration was performed with varying concentrations of renal antigen to assure appropriate amount of immuno nonanticomplementary globulin in the reaction mixture. A 1:20 dilution of the rabbit antiserum was used in the test.

Performance of Test. The test was performed on the semimicro technique using Cooke microtiter plates, dilutors, and pipettes (Cooke Instruments Ltd., Billinghurst, Sussex, England). Serial dilutions of $25-\mu$ l urine samples from $1: 2$ to $1: 254$ were carried out in Veronal buffer at $\mathrm{pH}$ 7.4. An equal volume of the diluted antiserum was added, the plates were tilted to assure mixing, covered with lids, and incubated for $60 \mathrm{~min}$ at $37^{\circ}$. After incubation they were cooled on ice for $10 \mathrm{~min}$ and $25 \mu \mathrm{l}$ ice-cold diluted human serum were added as source of complement. The plates were incubated again for $60 \mathrm{~min}$ at $37^{\circ}$ and then $25 \mu \mathrm{l} 1 \%$ suspension of antibody-coated sheep red blood cells were added. The plates were left for an additional $90 \mathrm{~min}$ at $37^{\circ}$ and read; $50 \%$ hemolysis was regarded as titration end point. The renal antigen was diluted $10 \mathrm{mg} / \mathrm{ml}$ and tested in parallel. The final results were calculated according to the following formula

\section{Discharge ratio $=$}

urine antigen concentration equivalent to renal antigen concentration factor $x$ creatinine concentration $(\mathrm{mg} / \mathrm{ml})$

Tables 1 and 2 show a typical experimental design.

\section{RESULTS}

Tables 3 and 4 are the summary of the results. They show the urinary excretion of renal antigen before and after factoring the results by the urinary concentration of creatinine. The actual antigen concentration of each urine sample was not specified; results were arbitrarily divided into several ranges of concentra-

Table 1. Titration of renal antigen versus urine samples ${ }^{1}$

\begin{tabular}{|c|c|c|c|c|c|c|c|c|}
\hline Sample & \multicolumn{8}{|c|}{ Dilution } \\
\hline Renal antigen ${ }^{2}$ & 0 & 0 & 0 & 0 & + & ++ & $++t+$ & ++++ \\
\hline Urine 2 & 0 & 0 & ++ & +++ & ++++ & +++ & ++++ & ++++ \\
\hline Urine 3 & 0 & 0 & 0 & 0 & + & ++ & $+++t$ & ++++ \\
\hline Urine 4 & ++ & ++++ & ++++ & ++++ & ++++ & ++++ & ++++ & +++ \\
\hline
\end{tabular}

${ }^{1}$ Final well volume $0.1 \mathrm{ml}: 25 \mu \mathrm{l}$ antiserum, $25 \mu \mathrm{l}$ antigen, $25 \mu \mathrm{l}$ complement, and $25 \mu \mathrm{l}$ sheep red blood cells. $++++: 100 \%$ hemolysis; +++ : $75 \%$ hemolysis; $++: 50 \%$ hemolysis; $+: 25 \%$ hemolysis; 0 : no hemolysis. Antiserum, complement, and antigen control wells gave ++++ hemolysis.

${ }^{2}$ Renal antigen concentration $10 \mathrm{mg} / \mathrm{ml}$; antiserum dilution $1: 20$, complement dilution $1: 12$. 
tion. It is apparent from Tables 1 and 2 that there is a wide distribution of the individual urinary antigen concentrations. After factoring the results by the urinary concentration of creatinine, the variability between samples decreased.

Table 3 shows that the distribution of urinary antigen concentrations was similar in groups $A, B$, and $D$; concentrations below $0.6 \mathrm{mg} / \mathrm{ml}$ were found in $87 \%, 84 \%$, and $83 \%$, respectively, of patients in these three groups. In contrast, only $53 \%$ of patients in group $C$ had a urinary antigen concentration below $0.6 \mathrm{mg} / \mathrm{ml}$. The difference between groups is highly significant $P\left(\mathrm{x}^{2}\right)<$ 0.005 .

In Table 4 factoring of the urinary antigen concentration by urinary creatinine concentration modified the results: patients in groups $B$ and $D$ now had higher titers as compared to those in group $A ; 56 \%$ and $63 \%$ of values were below $0.6 \mathrm{mg} / \mathrm{ml}$, as compared to $75 \%$, respectively. Statistical analysis showed that groups $B$ and $D$ did not differ significantly, although there was a significant difference between groups $B$ and $D$ on one hand and group $A$ on the other hand, $P\left(\mathrm{x}^{2}\right)=0.02$. In group $C$ the "corrected" concentration was considerably higher, and only

Table 2. Urinary antigen concentration (based on data from table 1)

\begin{tabular}{c|c|c|c|c}
\hline $\begin{array}{c}\text { Urine } \\
\text { sample }\end{array}$ & $\begin{array}{c}\text { End-point ti- } \\
\text { ter }\end{array}$ & $\begin{array}{c}\text { Urinary anti- } \\
\text { gen equiva- } \\
\text { lent, } \mathrm{mg} / \mathrm{ml}^{1}\end{array}$ & $\begin{array}{c}\text { Urinary renal } \\
\text { antigen con- } \\
\text { centration }= \\
\mathrm{Q}^{2}\end{array}$ & $\begin{array}{c}\text { Discharge ratio }= \\
\mathrm{Q} \div \text { urinary creati- } \\
\text { nine concentration, } \\
\mathrm{mg} / \mathrm{ml}\end{array}$ \\
\hline 1 & $1: 4$ & 0.625 & 0.03125 & 0.1 \\
2 & $1: 8$ & 1.250 & 0.0625 & 0.5 \\
3 & $1: 64$ & 10.00 & 0.50 & 0.66 \\
4 & $1: 2$ & 0.311 & 0.015 & 0.65 \\
5 & 0 & 0 & 0 & 0 \\
6 & $1: 8$ & 1.25 & 0.062 & 0.42 \\
\hline
\end{tabular}

1 The value for the urinary renal antigen equivalent was obtained by multiplying the original renal antigen concentration of $10 \mathrm{mg} / \mathrm{ml}$ by the ratio between the titration end-point of the antigen, and the titration end-point of the tested urine.

${ }^{2} \mathrm{Q}=$ The urinary antigen concentration was obtained by dividing the values for antigen equivalent by the concentration factor $(1 / 20)$.
$15 \%$ of patients had levels below $0.6 \mathrm{mg} / \mathrm{ml}$, differing significantly from the other three groups, $P\left(\mathrm{x}^{2}\right)<0.001$.

\section{DISCUSSION}

Numerous methods have been reported aiming at the determination of the site of urinary tract infection. Cystoscopy with ureteric catheterization and bladder washout is a reliable technique, but invasive and hardly applicable in a general pediatric practice $(7,18)$. Indirect methods include reliance on clinical signs and common laboratory investigations such as leukocyte count and ESR, urinary concentration capacity $(5,22)$, and patterns of reinfection $(16,20)$, as well as other more complex and less readily available methods, such as urinary excretion of fibrin degradation products $(21)$, enzyme excretion $(12,16)$, the measurement of serum levels of agglutinins to infecting Escherichia coli antigen $(4,23)$, and the search for antibody-coated bacteria in the urine $(10,19)$. Most of these methods do not, however, measure the extent of renal tissue damage, nor do they determine the time at which the inflammatory process is extinct. We hope that the studies performed with the present method may contribute to the asse'ssment of both parameters.

Complement fixation was, in our hands, the most satisfactory quantitative method for the performance of the present study. As with most serologic techniques, the results are only relative. Thus the results of the study are more meaningful in two instances: in the context of an epidemiologic study of large populations, or in longitudinal studies of individual patients. The present report deals with the first of these aspects, while the latter studies are in progress.

The results of the present study are consistent with the assumption that there is a continuous discharge of renal antigenic material into the urine of most subjects. Boss et al. (3) have reported similar findings. The origin of the renal material is not known, but might be the result of the normal wear and tear of the kidney. An accelerated rate of discharge proportional to the intensity of the disease is conceivable in the course of any destructive process. The excretion rate might be modified by medication or by the natural course of the disease itself.

Perusal of the tables of results shows the wide range of antigen concentration (milligrams per $\mathrm{ml}$ ) in the individual urine sam-

Table 3. Concentration of renal antigen in 220 urine samples (milligams per ml)

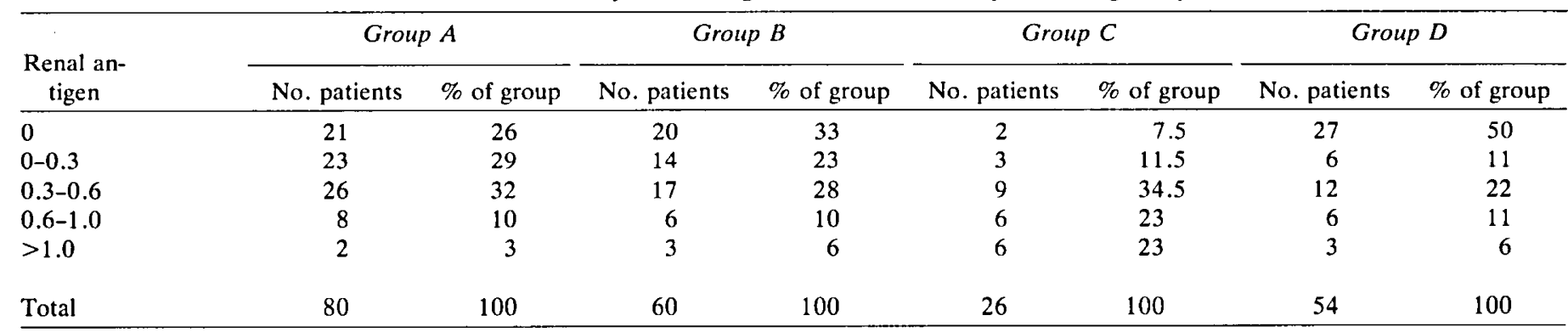

Table 4. Urinary discharge ratio (urinary renal antigen concentration* ((milligrams per ml) divided by urinary creatinine concentration (milligrams per $\mathrm{ml})$ ) in 220 urine samples

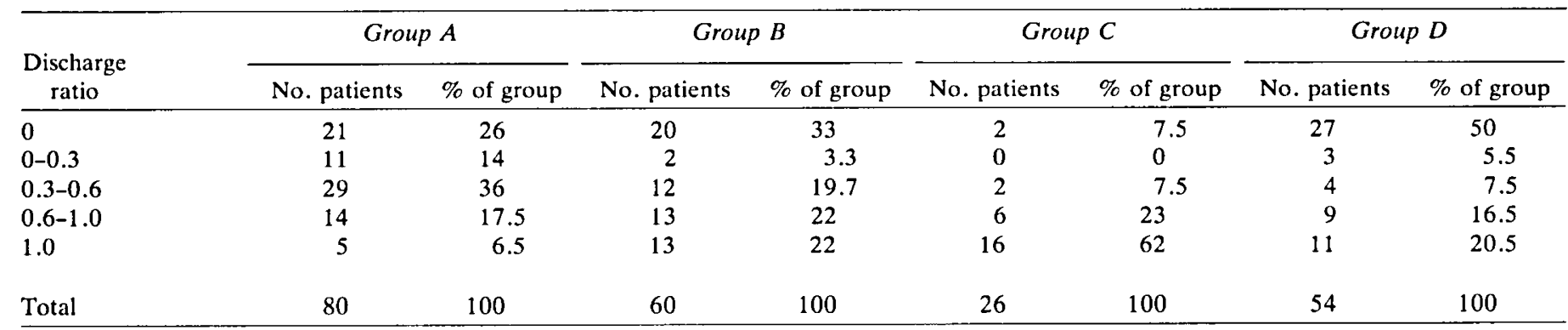


ples. These samples were not timed but were collected at a routine visit in the clinic, where no attempt was made to ensure uniformity of hydration. Moreover, the patients' concentration capacity could have been affected by the extent of renal damage. In an attempt to introduce a unifying factor, urinary creatinine concentration was used as a common denominator, and the variability of results diminished (14). This may not be the correct way of factoring antigen excretion, since the latter may be independent of urine flow and renal function. In the longitudinal studies presently in course an attempt will be made to measure antigen excretion per unit of time.

It is hard to conclude which antigen concentration is pathologic, and which is still in the realm of normal. If however, the upper "normal" limit of discharge ratio is set below 1 , then values above this limit are much more frequent in group $C$ than in either $A, B$, or $D$. However, even in group $C$ there are many patients with low discharge ratios, probably because this group comprises all patients with active urinary tract infection, including those with infection limited to the lower urinary tract, with little or no damage to the kidney proper. When discharge ratios were correlated with radiologic findings (intravenous urography and voiding cystourethragraphy), all patients in group $C$ with high discharge ratios were found to have vesicoureteric reflux, with or without signs of pyelonephritis. Lastly, some patients in group $A$ who were classified as "normal" had discharge ratios higher than 1.0. In the 2 years which have lapsed since the end of the first stage of this study, renal disease has become manifest in three out of the five patients in group $A$, who initially had unexplained high discharge ratios.

\section{CONCLUSION}

Urinary kidney-derived antigens were measured by a complement fixation technique in 220 children with and without active renal disease. When various groups of patients were compared, high antigen titers were found in a higher percentage among patients with active renal infections, or other noninfectious renal diseases. This method may serve to assess the activity of renal disease, and possibly also the extent of renal damage.

\section{REFERENCES AND NOTES}

1. Antoine, B., and Neveu, T.: Pathological urinary excretion of tissue macromolecules (histuria). J. Lab. Clin. Med., 71: 101 (1968).

2. Berggard, I.: Plasma proteins in normal human urine. In: Y. Manuel, J. P. Revillard, and H. Betuel: Proteins in Normal and Pathological Urine (S. Karger, Basel, 1970).

3. Boss, J. H., Dishon, T., Durst, A., and Rosenman, E.: Tissue antigen excreted into urine under normal and pathological conditions. Isr. J. Med. Sci., 9: 490 (1973).

4. Clark, H., Ronald, A. R., and Turck, M.: Serum antibody response in renal versus bladder bacteriuria. J. Infect. Dis., 123: 539 (1971).
5. Dishon, T., Rosenman, E., Durst, A., and Boss. J. H.: Excretion of organ specific tissue antigen in the urine of rats. Isr. J. Med. Sci., 6: 464 (1970)

6. Dishon, T., Rosenman, E., Durst, A., and Boss, J. H.: Urinary excretion of kidney antigens in rats with experimental glomerulonephritis and pyelonephritis. Exp. Mol. Path., 15: 126 (1971).

7. Fairley, K. F., Bond, A. G., Brown, R. B., et al.: Simple test to determine the site of urinary tract infection. Lancet, ii: 427 (1967).

8. Grant, G. H.: The proteins of normal urine. J. Clin. Path. 10: 360 (1957).

9. Introp, H. W., and Milgrom, F.: Thermostable kidney antigen and its excretion into urine. J. Immunol., 100: 1195 (1958).

10. Jones, S. R., Smith, J. W., and Sanford, J. P.: Localization of urinary tract infections by detection of antibody coated bacteria in urine sediment. $\mathrm{N}$. Engl. J. Med., 290: 591 (1973).

11. Kabat, E. A., and Mayers, M. M.: Experimental Immunochemistry. Ed. 2 (Charles C Thomas, Publisher, Springfield, Ill., 1961).

12. Leonard, C. D.: Urinary beta glucuronisidase in man: Relation to urinary specific gravity and creatinine concentration. Clin. Nephrol., 2: 41 (1974).

13. McPhaul, J. J., Jr., and Dixon, F. J.: Immunoreactive basement membrane antigen in normal human urine and serum. J. Exp. Med., 130: 1395 (1969).

14. Pollack, H.: Creatinine excretion as index for estimating urinary excretion of micronutrients or their metabolic and products. Amer. J. Clin. Nutr., 23: 865 (1970).

15. Ronald, A. R., Culter, R. E., and Turck, M.: Effect of bacteriuria on the renal concentration mechanisms. Ann. Int. Med., 70: 723 (1969).

16. Ronald, A. R., Silverblatt, F., Clark, H., Cutler, R. E., and Turck, M. Failure of urinary beta-glucoronidase activity to localize site of urinary tract infection, Appl. Microbiol., 21, 990 (1971).

17. Rosenman, E., Dishon, T., Durst, A., and Boss, J. H.: Urinary excretion of kidney antigens in experimental renal disease of the rat. Brit. J. Exp. Pathol., 52: 388 (1971).

18. Stamey, T. A., Govan, D. E., and Palmer. J. M.: The localization and treatment of urinary tract infections: The role of bactericidal urine levels as opposed to serum levels. Medicine, 44: 1 (1965).

19. Thomas, V., Shelokov, A., and Forland, M.: Antibody-coated bacteria in the urine and the site of urinary tract infection. N. Engl. J. Med., 290: 588 (1975).

20. Turck, M., Ronald, A. R., and Petersdorf, R. G.: Relapse and reinfection in chronic bacteriuria. I1. The correlation between site of infection and pattern of recurrence in chronic bacteriuria. New Engl. J. Med., 178: 422 (1968).

21. Whitworth, J. A., Fairley, K. F., McIvor, M. A., and Stubbs, A. R.: Urinary fibrin-degradation products and the site of urinary infection. Lancet, $i$ : 234 (1973).

22. Winberg, J.: Renal function studies in infants and children with acute nonobstructive urinary tract infection. Acta Pediat., 48: 577 (1959).

23. Winberg, J., Anderson, H. J., Hanson, L. A., et al.: Studies of urinary tract infection in infancy and childhood. I. Antibody response in different types of urinary tract infections caused by coliform bacteria. Brit. Med. J., ii: 524 (1963).

24. This study was approved by the ethical committee of our medical center as consistent with the requirements of the Helsinki Manifesto for the preservation of the rights of patients.

25. Presented in part at the Third International Symposium of Pediatric Nephrology, Washington D.C., September 1974.

26. This research was supported in part by Grant 101 of the Chief Scientist's office, Ministry of Health of Israel and a special grant from Mr. Benno Szpiro, Zug, Switzerland.

27. Requests for reprints should be addressed to: H. Boichis, M.D., Chairman of Pediatrics, Head, Pediatric Renal Unit, Chaim Sheba Medical Center, TelHashomer 52621 (Israel).

28. Received for publication July $16,1976$.

29. Accepted for publication March 9, 1977. 